\title{
Brainstem Amino Acid Neurotransmitters and Ventilatory Response to Hypoxia in Piglets
}

\author{
DOROTHY A. HEHRE, CARLOS J. DEVIA, EDUARDO BANCALARI, AND CLEIDE SUGUIHARA \\ Department of Pediatrics, University of Miami, Miller School of Medicine, Miami, Florida, 33136
}

\begin{abstract}
The ventilatory response to hypoxia is influenced by the balance between inhibitory (GABA, glycine, and taurine) and excitatory (glutamate and aspartate) brainstem amino acid (AA) neurotransmitters. To assess the effects of AA in the nucleus tractus solitarius (NTS) on the ventilatory response to hypoxia at 1 and $2 \mathrm{wk}$ of age, inhibitory and excitatory AA were sampled by microdialysis in unanesthetized and chronically instrumented piglets. Microdialysis samples from the NTS area were collected at 5-min intervals and minute ventilation $\left(\mathrm{V}_{\mathrm{E}}\right)$, arterial blood pressure $(\mathrm{ABP})$, and arterial blood gases $(\mathrm{ABG})$ were measured while the animals were in quiet sleep. A biphasic ventilatory response to hypoxia was observed in wk 1 and 2, but the decrease in $\mathrm{V}_{\mathrm{E}}$ at 10 and 15 min was more marked in wk 1. This was associated with an increase in inhibitory AA during hypoxia in wk 1. Excitatory AA levels were elevated during hypoxia in wk 1 and 2. Changes in $\mathrm{ABP}, \mathrm{pH}$, and $\mathrm{ABG}$ during hypoxia were not different between weeks. These data suggest that the larger depression in the ventilatory response to hypoxia observed in younger piglets is mediated by predominance of the inhibitory AA neurotransmitters, GABA, glycine, and taurine, in the NTS. (Pediatr Res 63: 46-50, 2008)
\end{abstract}

$\mathrm{T}^{\mathrm{s}}$ he difference in ventilatory response to hypoxia between neonatal and adult subjects is well documented (1-3). The ventilatory response to hypoxia during the neonatal period is characterized by an increase in ventilation (1-2 min) followed by a decrease in minute ventilation $\left(\mathrm{V}_{\mathrm{E}}\right)$ to values below or close to baseline levels. In contrast, a more sustained ventilatory response to hypoxia is described in adults (4). The initial increase in ventilation is mediated by the peripheral chemoreceptors, whereas subsequent changes are centrally mediated $(5,6)$.

The change from the neonatal to the adult ventilatory response is thought to occur during early postnatal life in most species $(7,8)$. Previous studies have demonstrated that this change in the ventilatory response occurs within the first 1-2 wk of life in piglets $(9-11)$.

Several mechanisms may be responsible for the ventilatory depression observed during hypoxia soon after birth. These include deterioration in lung mechanics (12), changes in metabolism (13), and a predominance of inhibitory over excitatory neurotransmitters in the CNS (14). Previous studies from our laboratory have demonstrated a role for amino acids (AA) in the hypoxic ventilatory response in newborn animals $(5,15-$ 17). The balance between excitatory AA, such as glutamate

Received March 14, 2007; accepted August 10, 2007.

Correspondence: Cleide Suguihara, M.D., University of Miami, Miller School of Medicine, Department of Pediatrics (R-131), P.O. Box 016960, Miami, FL 33101; e-mail: csuguihara@miami.edu

Supported by the University of Miami Project: New Born. and aspartate, and inhibitory AA, such as GABA and glycine, may influence the ventilatory response to hypoxia in the neonatal and postnatal periods. In newborn animals, it has been suggested that the increase in the release of the CNS inhibitory amino acid neurotransmitter GABA may be responsible for the hypoxic ventilatory depression $(9,16,18)$. However, it is also possible that the biphasic response in ventilation during hypoxia may be due to a reduction in the release of central excitatory AA neurotransmitters, glutamate, and aspartate, resulting in enhancement of the effects of inhibitory AA neurotransmitters, GABA and glycine $(15,17,19)$. Taurine, an inhibitory AA, is known to have hypoxic-protective properties. Taurine is at its highest concentration in the brain during the fetal and newborn periods and decreases from birth to adulthood (20). It may also play an important role in the regulation of ventilation during the neonatal period. To the best of our knowledge, there are no published data evaluating the relationship between nucleus tractus solitarius (NTS) excitatory and inhibitory amino acid levels with ventilation during hypoxia in different age groups.

We hypothesize that the postnatal maturation of the ventilatory response to hypoxia is determined by a change in the balance between inhibitory (GABA, glycine, and taurine) and excitatory (glutamate and aspartate) AA neurotransmitters in the brainstem respiratory areas. Therefore, the purpose of this study was to evaluate the ventilatory response to hypoxia in unanesthetized piglets at 1 and $2 \mathrm{wk}$ after birth and to simultaneously assess the changes in the extracellular levels of glutamate, aspartate, GABA, glycine, and taurine in the region of the NTS of the brainstem induced by hypoxia in these piglets.

\section{MATERIALS AND METHODS}

Surgical procedures. Newborn Yorkshire piglets (wk 1: $n=12$, age $4.3 \pm$ $1.4 \mathrm{~d}$, wt $1.60 \pm 0.40 \mathrm{~kg}$; wk $2: n=9$, age $10.6 \pm 1.5 \mathrm{~d}$, wt $2.2 \pm 0.6 \mathrm{~kg}$ ) were anesthetized with $2 \%$ isoflurane in oxygen using a nonrebreathing anesthesia mask for aseptic surgical procedures. Heart rate (HR) and oxygen saturation were measured by continuous pulse oximetry (model N-100, Nellcor Inc., Hayward, CA) and body temperature was monitored with a rectal thermistor (YSI Inc., Yellow Springs, $\mathrm{OH}$ ) during surgery. Body temperature was maintained by means of a heating pad. The femoral artery and vein were cannulated and catheters were secured in a pouch on the lower back of the animals. Each piglet was then placed in the prone position with its head fixed in a stereotaxic holder (model 1530, David Kopf, Tujunga, CA) for implantation of a guide cannula. The cannula was placed $1.5-1.8 \mathrm{~mm}$ left of the sagittal suture and $1.0-1.5 \mathrm{~mm}$

\footnotetext{
Abbreviations: AA, amino acid; ABP, arterial blood pressure; EOG, electrooculogram; HR, heart rate; NTS, nucleus tractus solitarius; $\mathbf{V}_{\mathbf{E}}$, minute ventilation; $\mathbf{V}_{\mathbf{T}}$, tidal volume
} 
anterior to the lambda and cemented to the skull with dental acrylic cement. This was later used for the placement of the microdialysis probe into the NTS on the day of the study. The measurements used for the placement of the probe were determined from a previous study in our laboratory (17).

EEG and electro-oculogram (EOG) were used to monitor sleep state. EEG electrodes consisted of insulated stainless steel wires (Cooner Wire Co., Chatsworth, CA) connected to bifrontal stainless steel screws, which were anchored $10 \mathrm{~mm}$ anterior and lateral to the bregma and insulated with dental acrylic cement. For EOG, a pair of insulated stainless steel wire electrodes were sewn at the outer canthus of the eye and used as a signal source and a third wire was used as a ground reference. The signals were amplified and recorded on an eight-channel recorder (model RS3800, Gould Instruments, Cleveland, $\mathrm{OH})$ and computer program.

Prophylaxis antibiotic, cefoxitin $(50 \mathrm{mg} / \mathrm{kg}$ i.v. twice daily), was given the day of surgery and up to $3 \mathrm{~d}$ postoperatively. Catheters were flushed with 20 units of heparinized saline daily. The animals were allowed to ambulate twice daily outside the pens.

Handling and care of the animals were in accordance with the guidelines of the National Institutes of Health and the study protocol was approved by the Animal Care Committee of the University of Miami.

Amino acid analysis. AA concentrations in the perfusate were analyzed by HPLC with electrochemical detection after precolumn derivatization. The stable $o$-phthaldehyde and $t$-butylthiol derivatives of amino acids were separated by gradient elution. The mobile phase for determination of the AA content consists of solvent A (67.8:27.4:4.7) and solvent B (15:45:40): acetate-acetonitrile-tetrahydrofuran (by volume; $\mathrm{pH} 6.8$ ). The gradient from 0 to $85 \%$ was run in $30 \mathrm{~min}$ at a flow rate of $0.8 \mathrm{~mL} / \mathrm{min}$. All work was done on a liquid chromatograph (model BAS 200, Bioanalytical Systems, West Lafayette, IN) equipped for gradient operation and amperometer detection.

Ventilatory analysis. Respiratory airflow was measured using a pneumotachograph attached to a customized facemask, a differential pressure transducer (model MP45; Validyne Engineering Co., Northridge, CA) and a pressure amplifier. The flow signal was integrated to obtain tidal volume $\left(\mathrm{V}_{\mathrm{T}}\right)$ using a Gould integrator. Minute ventilation $\left(\mathrm{V}_{\mathrm{E}}\right)$ was obtained by adding inspiratory volumes measured over a 1-min period. Bias flow was adjusted to meet the animal's airflow demands. The generated signals were recorded on the multichannel recorder and all signals were digitized (AT-Codas, DataQ Instruments, Akron, $\mathrm{OH}$ ) and stored into a personal computer.

Hemodynamic analysis. Arterial blood pressure (ABP) and HR were measured with a pressure transducer (model P-23 ID, Gould Instruments) throughout the study period.

Study protocol. Forty-eight to 72 hours after surgery, the animals were placed in a sling and kept in a thermoneutral environment. A microdialysis probe, $55 \mathrm{~mm}$ length, $3 \mathrm{~mm}$ polycarbonated membrane with a 20,000 D cutoff and a $0.4 \mathrm{~mm}$ diameter, was positioned through the guide. The probe was perfused continuously with an unbuffered Ringers solution that contained (mM) $140 \mathrm{NaCl}, 2.5 \mathrm{KCL}, 1.3 \mathrm{CaCl}_{2}$, and $0.9 \mathrm{MgCl}_{2} \cdot 6 \mathrm{H}_{2} \mathrm{O}$ via an infusion pump (BAS Bee Pump, Model MD-1001, Bioanalytical Systems, West Lafayette, IN) at a rate of $2.0 \mu \mathrm{L} / \mathrm{min}$. The dialysate was collected at 5-min intervals and the samples were frozen and stored at $-70^{\circ} \mathrm{C}$ and later analyzed for amino acid concentrations. At the end of each study, a fast green dye (5\%) was perfused through the microdialysis probe for post mortem confirmation of the probe position. The probe was considered to be properly placed if any portion of the distal probe was inside the NTS as described previously (17).

The animals were allowed to stabilize $90 \mathrm{~min}$ after the placement of the microdialysis probe. Thirty minutes into the stabilization period, the piglets were allowed to breathe through a customized airtight facemask. After $1 \mathrm{~h}$ of acclimatization, $\mathrm{ABP}, \mathrm{HR}$, arterial blood gases $(\mathrm{ABG}), \mathrm{V}_{\mathrm{E}}, \mathrm{V}_{\mathrm{T}}$, and respiratory rate (RR) were measured over $30 \mathrm{~min}$ and referred to as air values. Microdialysis samples were obtained throughout the study periods. After air measurements, animals were exposed to $10 \% \mathrm{O}_{2}$ (hypoxia) for $15 \mathrm{~min}$. All measurements were repeated at $1,5,10$, and $15 \mathrm{~min}$ of hypoxia. EEG and EOG were monitored to ensure that all measurements were obtained during nonrapid eye movement sleep, because sleep states can modify the ventilatory response to hypoxia in newborn animals (21).

Statistical analysis. Data are expressed as mean $\pm \mathrm{SD}$. Two-way ANOVA with repeated measures was used to compare cardiorespiratory and AA values during hypoxia between the two age groups. $p$ values $<0.05$ were considered significant. All statistical analysis was performed using SigmaStat 3.0.

\section{RESULTS}

Ventilation and amino acid neurotransmitters. Ventilation and AA results in hypoxia are expressed as percent change from air. Both age groups displayed a biphasic ventilatory response to hypoxia; however, a more marked decrease in ventilation during hypoxia was observed in wk 1 compared with wk 2 studies $(p<0.01)$ (Fig. 1). During the first week, ventilation increased at $1 \mathrm{~min}$ of hypoxia and then decreased to values slightly above baseline at $15 \min (9 \pm 16 \%) . \mathrm{V}_{\mathrm{T}}$ was mainly responsible for the decrease in $\mathrm{V}_{\mathrm{E}}$ from 5 min to 15 min of hypoxia (Table 1). However, in wk 2, a larger increase in ventilation was observed at $1 \mathrm{~min}$ of hypoxia, and ventilation was maintained well above baseline at $15 \min (33 \pm$ $21 \%$ ). This change in $\mathrm{V}_{\mathrm{E}}$ was primarily due to an increase in RR (Table 1).

Figure 2 represents the changes in brainstem inhibitory AA levels during hypoxia. During hypoxia, the levels of GABA ( $p<$ $0.04)$, glycine $(p<0.03)$, and taurine $(p<0.04)$ were significantly higher in wk 1 compared with wk 2 animals. During wk 1 , GABA levels had a minimal increase at $0-5$ min but increased further at 5-10 $\mathrm{min}$ and $10-15 \mathrm{~min}$. The levels of glycine also increased significantly during hypoxia in relation to air values. Taurine levels increased at $0-5 \mathrm{~min}$, peaked at 5-10 min, and decreased slightly at $10-15 \mathrm{~min}$.

Figure 3 represents the changes in excitatory AA levels during hypoxia. Aspartate and glutamate levels increased and maintained levels above air values during hypoxia in wk 1 and wk 2 animals.

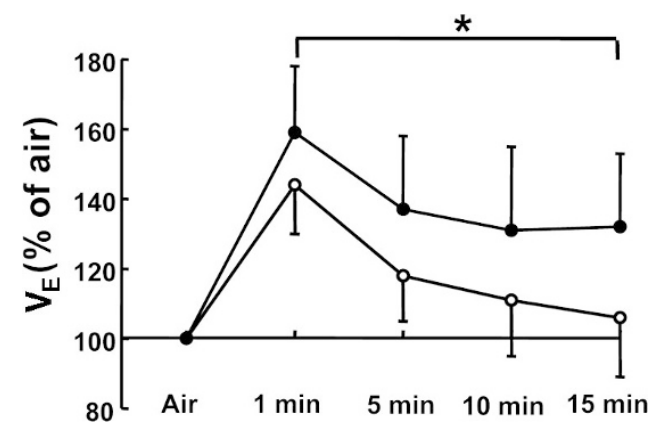

Figure 1. Ventilatory response to hypoxia (mean $\pm \mathrm{SD}$ expressed as percentage of air) at wk 1 and 2 after birth. A biphasic response to hypoxia is observed in both groups. However, there is a more marked decrease in ventilation in wk $1(\bigcirc)$ with a statistical significant difference when compared with wk 2()$^{*} p<0.01$; wk 1 vs wk 2).

Table 1. $A B G$, acid-base balance, $R R, V_{T}, V_{E}, A B P$, and $H R$ obtained in air and at 15 min of hypoxia at wk 1 and 2 after birth

\begin{tabular}{lccccc}
\hline & \multicolumn{2}{c}{ Week 1} & & \multicolumn{2}{c}{ Week 2} \\
\cline { 2 - 3 } \cline { 5 - 6 } \cline { 5 - 6 } & Air & Hypoxia & & Air & Hypoxia \\
\hline $\mathrm{pH}$ & $7.47 \pm 0.02$ & $7.53 \pm 0.03$ & & $7.46 \pm 0.02$ & $7.53 \pm 0.03$ \\
$\mathrm{Paco}_{2}, \mathrm{~mm} \mathrm{Hg}$ & $38 \pm 2$ & $33 \pm 4$ & & $38 \pm 6$ & $30 \pm 2$ \\
$\mathrm{Pao}_{2}, \mathrm{~mm} \mathrm{Hg}$ & $89 \pm 11$ & $30 \pm 4$ & & $92 \pm 11$ & $31 \pm 3$ \\
$\mathrm{BE}, \mathrm{mM} / \mathrm{L}$ & $4.4 \pm 2.0$ & $5.3 \pm 1.5$ & & $4.1 \pm 2.0$ & $4.0 \pm 3.0$ \\
$\mathrm{RR}, \mathrm{breaths} / \mathrm{min}$ & $52 \pm 21$ & $74 \pm 32$ & & $65 \pm 33$ & $85 \pm 41$ \\
$\mathrm{~V}_{\mathrm{T}}, \mathrm{mL} / \mathrm{kg}$ & $15.8 \pm 3$ & $12.0 \pm 2$ & & $11.2 \pm 4$ & $11.1 \pm 3^{*}$ \\
$\mathrm{~V}_{\mathrm{E}}, \mathrm{mL} / \mathrm{kg} / \mathrm{min}$ & $776 \pm 184$ & $846 \pm 240$ & & $628 \pm 118$ & $838 \pm 237^{*}$ \\
$\mathrm{ABP}, \mathrm{mm} \mathrm{Hg}$ & $77 \pm 9$ & $75 \pm 7$ & & $86 \pm 19$ & $88 \pm 18$ \\
$\mathrm{HR}, \mathrm{beats} / \mathrm{min}$ & $207 \pm 42$ & $248 \pm 27$ & & $206 \pm 22$ & $244 \pm 13$ \\
\hline
\end{tabular}

The changes in $\mathrm{V}_{\mathrm{E}}$ and $\mathrm{V}_{\mathrm{T}}$ with hypoxia are statistically significant between wk 1 vs wk 2 groups $(* p<0.01)$. There are no significant differences in ABG, acid-base balance, RR, ABP, and HR between the two age groups.

$* p<0.01$, wk 1 vs wk 2 by ANOVA. 


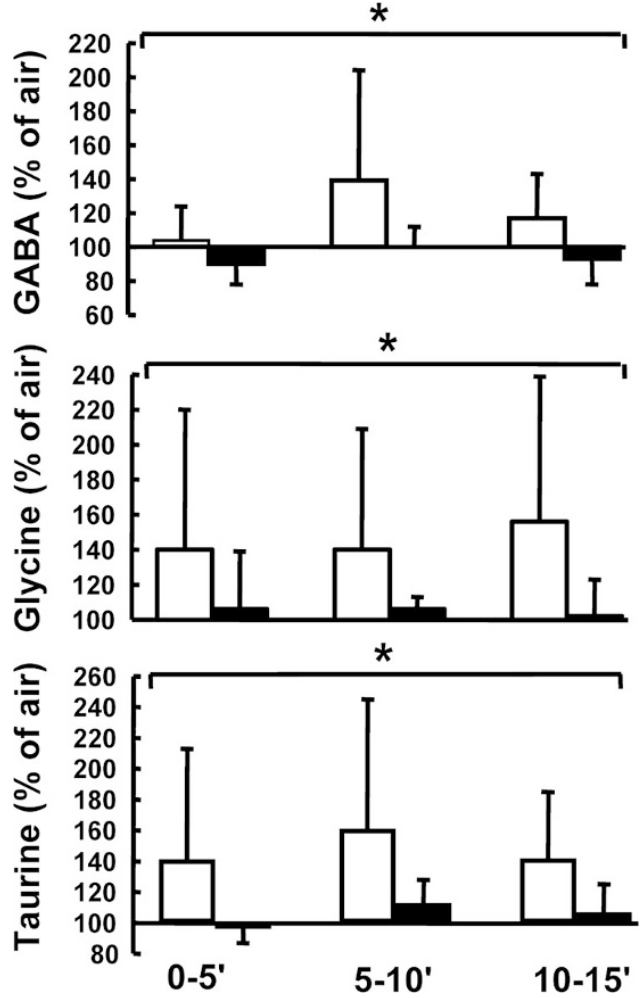

Figure 2. Mean values (SD) for GABA, glycine, and taurine levels in the NTS at wk 1 and 2 after birth (expressed as percentage of air) in response to hypoxia. The values for all three inhibitory AA are significantly lower in wk

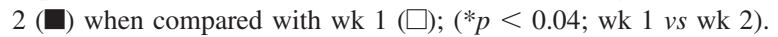

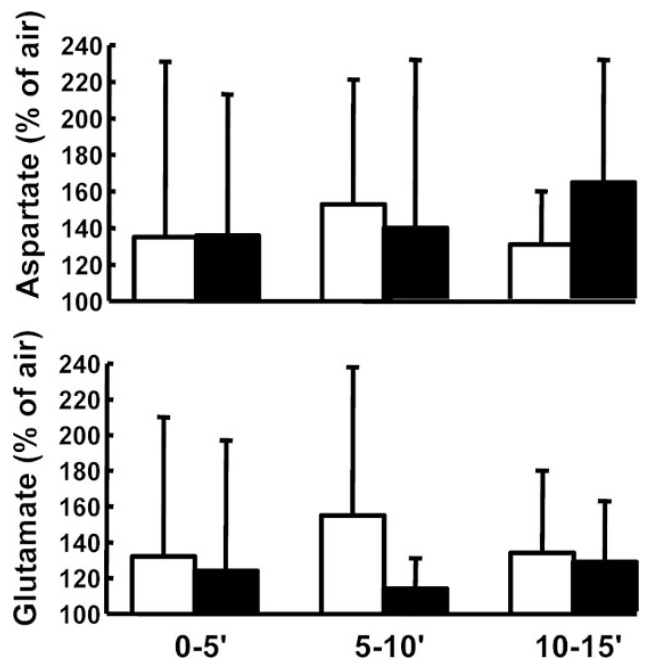

Figure 3. Mean values (SD) for aspartate and glutamate levels in the NTS at wk 1 and 2 after birth (expressed as percentage of air) in response to hypoxia. Aspartate and glutamate changes during hypoxia were not different between wk $1(\square)$ and wk 2 (ם).

$A B P, H R, A B G$, and acid base balance. Changes in HR and $\mathrm{ABP}$ with hypoxia were not different between the two study groups (Table 1). Changes in $\mathrm{pH}$, arterial $\mathrm{Po}_{2}\left(\mathrm{PaO}_{2}\right)$, arterial $\mathrm{PCO}_{2}\left(\mathrm{PaCO}_{2}\right)$, and base excess $(\mathrm{BE})$ with hypoxia were also similar in wk 1 and 2 (Table 1).

\section{DISCUSSION}

The present study demonstrates a biphasic ventilatory response during hypoxia in piglets during wk 1 and 2 of age, although the decrease in ventilation after the first minute was more marked in the younger animals. The increase in extracellular levels of inhibitory AA GABA, glycine, and taurine in the NTS during hypoxia was observed only in the piglets studied at wk 1, while the increase in excitatory AA aspartate and glutamate concentrations was similar in both age groups. This suggests that the ventilatory response to hypoxia may be determined by the balance between excitatory and inhibitory amino acid neurotransmitters in the brainstem.

GABA is an important inhibitory neurotransmitter in the mammalian CNS and acts through two main receptor subtypes: $\alpha$ and $\beta$. GABA $\alpha$ receptor is an integral component of a chloride channel complex and GABA $\beta$ receptor is coupled to potassium and calcium channels. GABA $\alpha$ receptor activation leads to membrane hyperpolarization by increasing the membrane conductance to chloride, whereas the activation of GABA $\beta$ receptor increases the membrane conductance to potassium, resulting in hyperpolarization of neurons and causing late long-lasting inhibitory postsynaptic potentials $(22,23)$.

The age when the effect of GABA on the CNS changes from depolarization to hyperpolarization appears to depend on the maturity of the animal species and area of the brain. In the newborn rat hippocampus, the GABA receptor response is depolarizing from birth to postnatal d 4 before switching to hyperpolarization and becoming strictly inhibitory at the end of the first post natal week (24). However, when GABA was applied to the $0-4 \mathrm{~d}$ newborn rat brainstem in vitro, a decrease in respiratory frequency was observed (25). When a higher concentration of GABA was given, spontaneous periodic activity was sometimes totally abolished. These data suggest that the physiologic effect of GABA may vary in the different regions of the brain.

It has been well documented that central amino acids change concentrations during hypoxia, and several studies have demonstrated that GABA is a major inhibitory amino acid neurotransmitter and is a central depressant of ventilation $(18,19,26,27)$.

Previous studies from our laboratory have demonstrated a depressant role of GABA on the ventilatory response to hypoxia in newborn piglets $(16,28)$. Huang et al. (16) studied the effect of GABA $\alpha$ and $\beta$ receptors in newborn piglets using the receptor blockers bicuculline and CGP-35348. An increase in ventilation during hypoxia was reported after administration of the two GABA blockers, suggesting that the role of GABA in the late hypoxic ventilatory depression is mediated through both main receptor subtypes. Additionally, bicuculline methiodide (which does not cross the blood brain barrier) was given during hypoxia and did not have an effect on ventilation. This was confirmed by Xiao et al. (28), who administered bicuculline methiodide into the cisterna magna in newborn piglets and reported a significant increase in minute phrenic output during hypoxia. These studies suggest that the depressant effect of GABA on ventilation is centrally mediated.

In the first week, GABA levels increased after $5 \mathrm{~min}$ of hypoxia, whereas hypoxia had little or no effect on GABA levels in the piglets studied at wk 2. Similar to these results, Tabata et al. (26) measured GABA concentrations during 
hypoxia from the NTS and showed a marked increase in GABA after 15 min of hypoxia in adult rats.

Glycine, similar to GABA $\alpha$ receptor, switches from excitatory effect during fetal life to inhibitory effect after birth and also is an integral part of a chloride channel/receptor complex. Unlike GABA, glycine peaks after birth and then declines with development. Glycine synthase and serine hydroxymethyl transferase, the primary enzymes for glycine synthesis in the brain, are active at birth $(29,30)$. In rats, glycine concentrations are highest during the first postnatal week in the brain and decline with age (31). Carpenter et al. (32) studied the developmental changes of the mRNA coding for GABA and glycine receptors in the rat cerebral cortex and reported that glycine is the main inhibitory neurotransmitter but is replaced by GABA during the first $2-3$ wk after birth. The numbers of GABA receptors were found to increase from low levels before birth to adult levels at about $3 \mathrm{wk}$ of age. In a pilot study, we have demonstrated that after administering strychnine, a glycine antagonist to neonatal piglets, there was a decrease in time to peak activity and interburst durations and an increase in the frequency of the phrenic nerve output. These findings suggest that at an early age, glycine plays an important role in determining the respiratory pattern and rhythm.

The basal concentration of taurine is at its highest level in the neonatal brain and decreases, depending on the species, 3to 4-fold by adulthood (20). In the present study, taurine levels were markedly increased with hypoxia during wk 1 , while in wk 2, taurine levels initially decreased and than slightly increased above baseline values. This response of taurine in older animals may be explained by the increase in glutamate concentration. Glutamate is a competitive inhibitor of the decarboxylase enzyme that converts cysteine sulfinic acid to hypotaurine, limiting the formation of taurine $(14,33)$. Hoop et al. (27) reported a transient decrease in taurine in intact adult rats when exposed to hypoxia followed by an increase to prehypoxic values at $15 \mathrm{~min}$.

In our study, glycine, GABA, and taurine increased with hypoxia in the younger animals. This can explain the depressed ventilatory response to hypoxia during the first week of life.

Glutamate and aspartate are major excitatory neurotransmitters and are present in high concentrations in the CNS. We have previously demonstrated that an increase in glutamate concentration was in part responsible for the increase in ventilation during hypoxia in unanesthetized 6-d-old piglets (5). In contrast, in a rodent model, Ohtake et al. (34) demonstrated that after administration of MK-801, a NMDA receptor antagonist, there was no effect on the hypoxic ventilatory response in young rats $(5$ and $10 \mathrm{~d})$ but at $15 \mathrm{~d}$ increased $\mathrm{V}_{\mathrm{E}}$ and RR. The results from the present study and previous studies from our laboratory suggest that the respiratory control in piglets is more mature than in developing rats (5).

The excitatory effect of aspartate on the respiratory system has been reported in adult cats and rats $(35,36)$. In the neonatal piglets, Navarro et al. (15) administered L-aspartate and produced a significant increase in the ventilatory response to hypoxia, confirming the excitatory effect this AA has on respiratory control. In the present study, glutamate and aspar- tate levels in the NTS increased during hypoxia in both age groups concurrent with the initial increase in ventilation. However, during the later phase of the ventilatory response, the increase in excitatory AA was not enough to override the effect of the inhibitory AA and ventilation declined.

There may be other neurochemicals, such as adenosine, opioids, and prostaglandins, that play a role in the ventilatory response to hypoxia during development $(11,37)$. Adenosine is an inhibitory amino acid that has been shown to depress respiration in early life. Mayer et al. (37) studied the effects of adenosine $\mathrm{A}_{2 \mathrm{~A}}$-receptor activation in developing rats and reported that the respiratory inhibitory effect of $\mathrm{A}_{2 \mathrm{~A}}$-receptor activation is age dependent. Additionally, bicuculline, was given before and after $\mathrm{A}_{2 \mathrm{~A}}$-receptor agonist (CGS) injection and prevented the inhibitory response observed after CGS suggesting that $\mathrm{A}_{2 \mathrm{~A}}$-receptor activation is mediated through the GABAergic pathway suggesting that there is an interaction between different neurotransmitters and neuromodulators during development (37).

In summary, this study extends the knowledge of the role of central inhibitory and excitatory amino acid neurotransmitters released in the NTS during the ventilatory response to hypoxia, and demonstrates that the balance between inhibitory and excitatory amino acids varies during the neonatal period and may play an important role in the ventilatory response to hypoxia. The results suggest that the biphasic ventilatory response to hypoxia in newborn piglets is in part modulated by increased concentrations of inhibitory amino acids in the first week of life.

Acknowledgments. The authors thank Jian Huang, M.D., for his technical assistance with the analysis of amino acids by HPLC.

\section{REFERENCES}

1. Sankaran K, Wiebe H, Seshia MM, Boychuk RB, Cates D, Rigatto H 1979 Immediate and late ventilatory response to high and low $\mathrm{O} 2$ in preterm infants and adults subjects. Pediatr Res 13:875-878

2. Weil JV, Byrne-Quinn E, Sodal IE, Friesen WO, Underhill B, Filley GF, Grover RF 1970 Hypoxic ventilatory drive in normal man. J Clin Invest 49:1061-1072

3. Suguihara C, Hehre D, Huang J, Devia C, Bancalari E 1996 Decreased ventilatory response to hypoxia in sedated newborn piglets prenatally exposed to cocaine. J Pediatr 128:389-395

4. Georgopoulos D, Walker S, Anthonisen NR 1989 Increased chemoreceptor output and ventilatory response to sustained hypoxia. J Appl Physiol 67:1157-1163

5. Lin J, Suguihara C, Huang J, Hehre D, Devia C, Bancalari E 1996 Effect of $\mathrm{N}$-methyl-D-aspartate receptor blockade on hypoxic ventilatory response in unanesthetized piglets. J Appl Physiol 80:1759-1763

6. Blanco CE, Hanson MA, Johnson P, Rigatto H 1984 Breathing pattern of kittens during hypoxia. J Appl Physiol 56:12-17

7. Bureau MA, Begin R 1982 Postnatal maturation of the respiratory response to $\mathrm{O} 2$ in awake newborn lambs. J Appl Physiol 52:428-433

8. Gozal D, Gozal E, Torres JE, Gozal YM, Nuckton TJ, Hornby PJ 1997 Nitric oxide modulates ventilatory responses to hypoxia in the developing rat. Am J Respir Crit Care Med 155:1755-1762

9. Miller MJ, Haxhiu MA, Haxhiu-Poskurica B, Dreshaj IA, DiFiore JM, Martin RJ 2000 Recurrent hypoxia exposure and reflex responses during development in the piglet. Respir Physiol 123:51-61

10. Akay M, Lipping T, Moodie K, Hoopes PJ 2002 Effects of hypoxia on the complexity of respiratory patterns during maturation. Early Hum Dev 70:55-71

11. Moss IR, Runold M, Dahlin I, Fredholm BB, Nyberg F, Lagercrantz H 1987 Respiratory and neuroendocrine responses of piglets to hypoxia during postnatal development. Acta Physiol Scand 131:533-541

12. Fisher JT, Mortola JP 1980 Statics of the respiratory system in newborn mammals. Respir Physiol 41:155-172

13. Mortola JP, Rezzonico R 1988 Metabolic and ventilatory rates in newborn kitten during acute hypoxia. Respir Physiol 73:55-68 
14. Burton MD, Kazemi H 2000 Neurotransmitters in central respiratory control. Respir Physiol 122:111-121

15. Navarro H, Suguihara C, Soliz A, Hehre D, Huang J, Bancalari E 1998 Effect of L-aspartate on the ventilatory response to hypoxia in sedated newborn piglets. Biol Neonate 73:387-394

16. Huang J, Suguihara C, Hehre D, Lin J, Bancalari E 1994 Effects of GABA receptor blockade on the respiratory response to hypoxia in sedated newborn piglets. J Appl Physiol 77:1006-1010

17. McCormick A, Suguihara C, Huang J, Devia C, Hehre D, Bruce J, Bancalari E 1998 Depressed ventilatory response to hypoxia in hypothermic newborn piglets: role of glutamate. J Appl Physiol 84:830-836

18. Kazemi H, Hoop B 1991 Glutamic acid and gamma-aminobutyric acid neurotransmitters in central control of breathing. J Appl Physiol 70:1-7

19. Soto-Arape I, Burton M, Kazemi H 1995 Central amino acid neurotransmitters and the hypoxic ventilatory response. Am J Respir Crit Care Med 151:1113-1120

20. Sturman JA 1988 Taurine in development. J Nutr 118:1169-1176

21. Phillipson EA, Bowes G. 1986 Control of breathing during sleep. In: Cherniak NS, Widdicombe JG (eds) Handbook of Physiology. Sec. 3, Respiration. Control of Breathing, Vol. 2. American Physiological Society, Bethesda, MD, pp 649-689

22. Bowery N 1989 GABAB-receptors and their significance in mammalian pharmacology. Trends Pharmacol Sci 10:401-407

23. Nicoll RA 1988 The coupling of neurotransmitter receptors to ion channels in the brain. Science 241:545-551

24. Rivera C, Voipio J, Payne J, Ruusuvuori E, Lahtinen H, Lamsa K, Pirvola U, Saarma M, Kaila K 1999 The K+/Cl- co-transporter KCC2 renders GABA hyperpolarizing during neuronal maturation. Nature 397:251-255

25. Murakoshi T, Suzue T, Tamai S 1985 A pharmacological study on respiratory rhythm in the isolated brainstem-spinal cord preparation of the newborn rat. Br J Pharmacol 86:95-104

26. Tabata M, Kurosawa H, Kikuchi Y, Hida W, Ogawa H, Okabe S, Tun Y, Hattori T, Shirato K 2001 Role of GABA within the nucleus tractus solitarii in the hypoxic ventilatory decline of awake rats. Am J Physiol Regul Integr Comp Physio 281:R1411-R1419

27. Hoop B, Beagle JL, Maher TJ, Kazemi H 1999 Brainstem amino acid neurotransmitters and hypoxic ventilatory response. Respir Physiol 118:117-129

28. Xiao Q, Suguihara C, Hehre D, Devia C, Huang J, Bancalari E 2000 Effects of GABA receptor blockade on the ventilatory response to hypoxia in hypothermic newborn piglets. Pediatr Res 47:663-668

29. Shank RP, Aprison MH 1970 The metabolism in vivo of glycine and serine in eight areas of the rat central nervous system. J Neurochem 17:1461-1474

30. Lahoya JL, Benavides J, Ugarte M 1980 Glycine metabolism and glycine synthase activity during the postnatal development of rat brain. Dev Neurosci 3:75-80

31. Benavides J, Lopez-Lahoya J, Valdivieso F, Ugarte M 1981 Postnatal development of synaptic glycine receptors in normal and hyperglycinemic rats. J Neurochem 37:315-320

32. Carpenter MK, Parker I, Miledi R 1988 Expression of GABA and glycine receptor by messenger RNAs from the developing rat cerebral cortex. Proc R Soc Lond B Biol Sci 234:159-170

33. Saransaari P, Oja SS 2000 Modulation of the ischemia-induced taurine released by adenosine receptors in the developing and adult mouse hippocampus. Neuroscience 97:425-430

34. Ohtake PJ, Simakajornboon N, Fehniger MD, Xue YD, Gozal D 2000 N-Methyl$\mathrm{D}$-aspartate receptor expression in the nucleus tractus solitarii and maturation of hypoxic ventilatory response in the rat. Am J Respir Crit Care Med 162:1140-1147

35. Toleikis JR, Wang L, Boyarsky LL 1979 Effects of excitatory and inhibitory amino acids on phasic respiratory neurons. J Neurosci Res 4:225-235

36. Schlenker EH, Goldman M 1988 Acute effects of aspartic acid on ventilation of male and female rats. Physiol Behav 42:313-318

37. Mayer CA, Haxhiu MA, Martin RJ, Wilson CG 2006 Adenosine A2A receptor mediate GABAergic inhibition of respiration in immature rats. J Appl Physiol 100:91-97 